\title{
Caroline Waerzeggers. "Priestly Courses and the Administration of Time in Neo-Babylonian Temples"
}

\section{Olga V. Popova}

\section{OpenEdition}

Journals

\section{Édition électronique}

URL : https://journals.openedition.org/abstractairanica/53414

DOI : 10.4000/abstractairanica. 53414

ISSN : 1961-960X

Éditeur :

CNRS (UMR 7528 Mondes iraniens et indiens), Éditions de l'IFRI

\section{Référence électronique}

Olga V. Popova, "Caroline Waerzeggers." Priestly Courses and the Administration of Time in NeoBabylonian Temples" ", Abstracta Iranica [En ligne], Volume 42-43 | 2021, document 48, mis en ligne le 30 décembre 2021, consulté le 26 décembre 2022. URL : http://journals.openedition.org/ abstractairanica/53414 ; DOI : https://doi.org/10.4000/abstractairanica.53414

Ce document a été généré automatiquement le 26 décembre 2022.

Tous droits réservés 


\title{
Caroline Waerzeggers. "Priestly Courses and the Administration of Time in Neo-Babylonian Temples"
}

\author{
Olga V. Popova
}

\section{RÉFÉRENCE}

Caroline Waerzeggers. "Priestly Courses and the Administration of Time in NeoBabylonian Temples" in T. Ganzel, S.E. Holtz (eds.). Contextualizing Jewish Temples. Leiden/Boston: Brill, 2020, p. 23-48.

1 Dans son article, Caroline Waerzeggers compare le système des prébendes (rotation du travail sacerdotal dans les temples babyloniens du $1^{\mathrm{er}}$ millénaire av. J.-C.) avec le mishmarot du Second Temple de Jérusalem. Ce dernier était basé sur la rotation de vingt-quatre familles qui accomplissaient le service dans un ordre fixe. Le caractère différent des sources rend la comparaison difficile, mais permet de contextualiser les deux cas.

Les ressemblances résident dans l'existence même du système de rotation, dans le rôle joué par des maisons paternelles dans ce système (batey avot et bit-abi) et dans la persistance des droits ancestraux sur les créneaux de service. Les différences sont aussi nombreuses. Le système de mishmarot avait, par exemple, une grande importance dans la société judéenne et fonctionnait comme système de datation, ce qui n'a jamais été le cas en Babylonie.

3 Caroline Waerzeggers étudie la division temporelle des services prébendaires babyloniens. Cette tâche se révèle d'autant plus difficile qu'à force de divisions d'héritages, de ventes et d'autres transactions, les fractions de prébendes étaient parfois infimes, ce qui rend la division d'origine impossible à saisir. Les prébendes les plus prestigieuses, donnant accès aux statues divines, étaient non-calendaires. En 
pratique, une division mensuelle des droits de service entre différentes familles ancestrales était possible.

4 Les fréquences auxquelles les autres prébendiers accomplissaient leurs services en Babylonie pouvaient être différentes et fonctionner sur une période trimestrielle, mensuelle ou de šapattu (quinze jours). Toutes les rotations connues étaient basées sur le calendrier normalisé de 360 jours, soit douze mois de 30 jours, ne tenant pas compte de l'alternance entre les mois lunaires de 29 et 30 jours, ni des éventuels mois intercalaires. Les particularités et les difficultés de ces systèmes forment le centre d'intérêt de l'article en question.

\section{AUTEURS}

OLGA V. POPOVA

Institute of Oriental Studies, Russian Academy of Sciences 